\title{
Transformasi Citra Biner Menggunakan Metode Thresholding Dan Otsu Thresholding
}

\author{
Syamsul Bhahri ${ }^{1}$, Rachmat ${ }^{2}$ \\ ${ }^{1}$ Teknik Informatika, ${ }^{2}$ Manajemen Informatika \\ ${ }^{1}$ STMIK Kharisma Makassar, ${ }^{2}$ Politeknik Informatika Nasional (POLINAS) Makassar \\ ${ }^{1}$ syamsulbahri@kharisma.ac.id, ${ }^{2}$ rachmat27udinus@gmail.com
}

\begin{abstract}
Abstrak
Thersholding merupakan salah satu metode sederhana dalam transformasi citra dari citra grayscale untuk membentuk citra biner, sebuah citra digital yang hanya memiliki dua kemungkinan warna pixelnya hitam dan putih, " jika nilainya berada antara dua nilai threshold dan threshold outside dimana adalah kebalikan dari threshold inside. Biasanya pixel object diberi nilai 1 sementara pixel background diber inilai 0 . Proses awal yang banyak dilakukan dalam image processing adalah mengubah citra berwarna menjadi citra grayscale, hal ini digunakan untuk menyederhanakan model citra. Citra berwarna terdiri dari 3 layer matrik yaitu Rlayer, Glayer dan Blayer. Sehingga untuk melakukan prosesproses selanjutnya tetap diperhatikan tiga layer di atas. Sehingga konsep itu diubah dengan mengubah 3 layer di atas menjadi 1 layer matrik grayscale dan hasilnya adalah citra grayscale Sebuah metode sederhana akan memilih nilai rata-rata atau nilai tengah, dengan pemikiran jika pixel object lebih terang dari pada background, pixel tersebut juga lebih terang dari rata-rata background tersebut. Sebuah pendekatan mutakhir adalah dengan membentuk histogram dari intensitas pixel dan menggunakan titik lembah sebagai nilai ambang. Dalam penelitian ini akan dibahas mengolahan citra digital yang akan ditransformasi dari penelitian ini dengan menggunakan Metode Thresholding didapatkan accuracy 39,22 $\%$ dan dilakukan gray thresholding didapatkan nilai accuracy $54,51 \%$.
\end{abstract}

\section{Kata Kunci :Thresholding, Metodethresholding, Citra, KompresiCitra}

\begin{abstract}
Thersholding is one simple method in image transformation from grayscale imagery to form a binary image, a digital image that only has two possible black and white pixel colors, "if the value is between the two threshold values and the outside threshold which is the opposite of the inside threshold. Usually the pixel object is given a value of 1 while the background pixel is valued at 0 . The initial process that is mostly done in image processing is to convert the color image to grayscale image, this is used to simplify the image model. Color images consist of 3 matrix layers, namely Player, Player and Player. So to do the process, the next three layers are still considered. So that the concept is changed by changing the 3 layers above into 1 gray-scale matrix layer and the result is grayscale image. A simple method will choose the average value or middle value, thinking if the pixel object is brighter than the background, the pixel also brighter than the average background. A recent approach is to form a histogram of pixel intensity and use the valley point as a threshold value. In this study will be discussed the processing of digital images that will be transformed from this study using the Thresholding Method obtained 39.22\% accuracy and gray thresholding performed accuracy value of $54.51 \%$.
\end{abstract}

Keywords: Thresholding, Method of thresholding, Citra, Compression Image

\section{PENDAHULUAN}

Program Matlab merupakan aplikasi pemrograman yang telah dikenal dalam pembuatan aplikasi penunjang penelitian. Matlab dalam pengolahan citra digital menyediakan bermacam tools yang akan mempersingkat waktu penulisan program sehingga peneliti lebih berfokus pada hasil dan inovasi penelitian. Thresholding adalah metoda paling sederhana dari segmentasi citra. Dari citra grayscale, thresholdingdapatdigunakanuntukmembentukcitrabiner. Sebuah citra biner adalah sebuah citra digital yang hanya memiliki dua kemungkinan nilai untuk tiap pixel. Kedua warna tersebut adalah hitam dan putih. Thersholding adalah fungsi matematika yang memotong-motong data menjadi kumpulan-kumpulan frekuensi yang berbeda, sehingga masing-masing komponen tersebut dapat dipelajari dengan menggunakan skala resolusi yang 
berbeda. Beberapa penerapan transformasi Thresholding pada pengolahan citra digital antara lain preprocessing pengenalan sidikjari, reduksi noise pada citra, steganografi, biometrika dan lain sebagainya. Oleh karena itu dirasakan penting untuk mengangkat bagaimana penerapan transformasi Thresholding dan thresholding dalam pengolahancitra digital menggunakan matlab.

Dalam bidang pengolahan citra, istilah citra mengacu pada suatu fungsi intensitas dalam bidang dua dimensi. Pemrosesan citra menggunakan komputer membutuhkan citra digital sebagai masukannya. Oleh karena itu, kita mengenal beberapa macam format citra digital, yang masing-masing memiliki format penyimpanan dan pembacaan data yang berbeda-beda. Proses mengubah citra ke bentuk digital bisa dilakukan dengan beberapa perangkat, misalnya scanner, kamera digital, dan handycam. Ketika sebuah citra sudah diubah ke dalam bentuk digital (selanjutnya disebut citra digital), bermacam-macam proses pengolahan citra dapat diperlakukan terhadap citra tersebut.

Tujuan segmentasi citra yaitu memisahkan wilayah objek dengan wilayah lain berdasarkan kesamaan atribut citra agar mudah dianalisis dalam rangka mengenali objek untuk suatu keperluan. Pada penelitian ini menggunakan MATLAB untuk membuat aplikasi toolbox GUI sehingga memudahkan penelitian ini serta sebagai media dokumetasi untuk penelitian selanjutnya. Metode yang paling sederhana untuk proses segmentasi yaitu dengan image thresholding atau pengambangan citra. Pada penelitian ini digunakan metode otsu thresholding dimana metode thresholding dapat membagi histogram citra keabuan ke dalam dua daerah yang berbeda secara otomatis.

Rancangan aplikasi pada penelitian ini menggunakan aplikasi GUI yaitu dirancang melalui program Matlab R2016b yang dapat mengolah citra dengan ukuran berapapun untuk dilakukan proses segmentasi citra. Citra yang diolah yaitu citra daun dimana akan melalui proses segmentasi dengan metode otsu thresholding dan akan melalui proses morfologi dengan pendekatan operasi erosi untuk mendapatkan hasil citra tersegmen dengan maksimal. Pada aplikasi GUI akan menampilkan citra asli, citra keabuan (grayscale), citra hasil segmentasi dengan otsu thresholding dan citra hasil proses morfologi dengan pendekatan operasi erosi.

Untuk mengidentifikasi sebuah objek dalam suatu citra perlu dilakukan proses segmentasi. 2

Segmentasi citra merupakan teknik untuk membagi suatu citra menjadi beberapa wilayah sesuai kemiripan atribut. Metode yang paling sederhana untuk proses segmentasi yaitu dengan image thresholding atau pengambangan citra. Sehingga metode thresholding lebih sederhana karena wilayah objek diatur dengan warna putih sedangkan sisanya diatur dengan warna hitam atau sebaliknya. Namun terdapat kelemahan dari teknik thresholding ini, yaitu nilai ambang harus diberikan secara manual atau coba-coba. Yang mana proses segmentasi menjadi tidak efisien. Sehingga pada penelitian ini digunakan metode otsu thresholding dimana metode thresholding dapat membagi histogram citra gray level ke dalam dua daerah yang berbeda secara otomatis. Penghitungan otsu thresholding terhadap nilai ambang yaitu secara otomatis berdasarkan citra masukan. Analisis diskriminan merupakan pendekatan yang digunakan pada metode otsu thresholding, dengan menentukan suatu variabel yang dapat membedakan antara dua atau lebih kelompok yang muncul secara alami. Untuk memisahkan objek dengan latar belakang analisis diskriminan akan memaksimumkan variabel tersebut. Dengan demikian, Metode otsu thresholding cocok untuk mencari nilai ambang dari sebuah citra serta mendapatkan hasil citra tersegmen yang maksimal.

\section{LANDASAN TEORI}

Thresholding[1] adalah metoda paling sederhana dari segmentasi citra. Dari citra grayscale, thresholding dapat digunakan untuk membentuk citra biner. Sebuah citra biner adalah sebuah citra digital yang hanya memiliki dua kemungkinan nilai untuk tiap pixel. Kedua warna tersebut adalah hitam dan putih.[3] Warna yang digunakan untuk object dalam citra. Selama proses thresholding, masing-masing pixel dalam sebuah citra ditandai sebagai pixel object jika nilai mereka lebih besar dari sebuah nilai threshold dikenal sebagai threshold above. Varian mencakup juga threshold below dimana kebalikan dari threshold above.[4] Threshold inside, dimana sebuah pixel diberi label "object" jika nilainya berada antara dua nilai threshold dan threshold outside dimana adalah kebalikan dari thresholdinside. Biasanya pixel object JURNAL SISTEM INFORMASI DAN TEKNOLOGI INFORMASI Vol. 7, No. 2, Oktober 2018 
diberinilai 1 sementara pixel background diberinilai 0. Pada akhirnya sebuah image biner dibentuk dengan member warnatiap pixel dengan putih atau hitam tergantung pada label dari pixel. Parameter kunci dalam proses thresholding adalah pemilihan dari nilai threshold. Ada beberapa metode yang berbeda dalam memilih sebuah nilai threshold.[2]

Otsu thresholding merupakan metode segmentasi yang sederhana dalam teknik segmentasi, sehingga dapat lebih mudah dalam melakukan pembagian wilayah wilayah yang homogen berdasarkan kriteria keserupaan untuk mengenali objek. Proses sebelum dilakukan pengamatan terhadap citra hasil segmentasi, terlebih dahulu harus melalui proses input citra, agar mudah ke proses selanjutnya. Proses selanjutnya adalah melakukan penambahan kecerahan pada citra agar memperbaiki kualitas citra. Setelah itu dilakukan proses segmentasi citra dengan metode otsu thresholding dan melalui pendekatan analisis diskriminan sehingga dapat memaksimumkan variabel tersebut agar objek dengan latar belakang dapat terpisah secara otomatis. Untuk lebih memaksimalkan hasil citra tersegmen dilakukan proses morfologi, pada penelitian ini morofologi dilakukan dengan operasi erosi. Untuk mengetahui lebih jelas batas ambang sebuah citra setelah melalui proses segmentasi yaitu dengan menggunakan histogram, serta dilakukan penghitungan validasi dengan metode PSNR dan MSE untuk mengetahui tingkat kesuksesan dalam proses segmentasi.

User dapat memilih nilai threshold secara manual, atau sebuah algoritma thresholding dapat menghitung sebuah nilai secara otomatis, yang dikenal sebagai thresholding otomatis. Sebuah metode sederhana akan memilih nilai rata-rata atau nilai tengah, dengan pemikiran jika pixel object lebih terang daripada background, pixel tersebut juga lebih terang dari rata-rata background tersebut. Sebuah pendekatan mutakhir adalah dengan membentuk histogram dari intensitas pixel dan menggunakan titik lembah sebagai nilai ambang.[5] Pendekatan histogram mengasumsikan bahwa ada sebuah nilai rata-rata dari pixel background dan pixel object, tapi bahwa nilai pixel actual memiliki variasi di antara nilai rata-rata tersebut. Selama proses thresholding, masing-masing pixel dalam sebuah citra ditandai sebagai pixel object jika nilai mereka lebih besar dari sebuah nilai threshold dikenal sebagai threshold above.

Varian mencakup juga threshold below dimana kebalikan dari threshold above. [6] Threshold inside, dimana sebuah pixel diberi label "object" jika nilainya berada antara dua nilai threshold dan threshold outside dimana adalah kebalikan dari thresholdinside. Biasanya pixel object diberi nilai 1sementara pixel background diberinilai 0.[7] Padaakhirnya sebuah image binerdi bentuk dengan member warnatiap pixel dengan putih atau hitam tergantung pada label dari pixel. Parameter kunci dalam proses thresholding adalah pemilihan dari nilai threshold.

Ada beberapa metode yang berbeda dalam memilih sebuah nilai threshold.[8] User dapat memilih nilai threshold secara manual, atau sebuah algoritma thresholding dapat menghitung sebuah nilai secara otomatis, yang dikenal sebagai thresholding otomatis. Sebuah metode sederhana akan memilih nilai rata-rata atau nilai tengah, dengan pemikiran jika pixel object lebih terang daripada background, pixel tersebut juga lebih terang dari rata-rata background tersebut. Sebuah pendekatan mutakhir adalah dengan membentuk histogram dari intensitas pixel dan menggunakan titik lembah sebagai nilai ambang. Pendekatan histogram mengasumsikan bahwa ada sebuah nilai rata-rata dari pixel background dan pixel object, tapi bahwa nilai pixel actual memiliki variasi diantara nilai rata-rata tersebut. Dan pengetahuan spesifik terhadap sebuah citra dan pengetahuan spesifik terhadap sebuah citra adalah melawan noise citraa dalah metode iterative sebagai berikut :

1. Sebuah nilai threshold $(\mathrm{T})$ dipilih, hal ini dapat dilakukan secaraaca katau berdasarkan metode yang diinginkan.

2. Citra disegmentasi berdasarkan pixel object dan background seperti dijelaskan di atas membentuk dan himpunan :

1. $G_{1}=\{\mathrm{f}(\mathrm{m}, \mathrm{n}): \mathrm{f}(\mathrm{m}, \mathrm{n})>\mathrm{T}\}($ Object pixel)

2. $G_{2}=\{\mathrm{f}(\mathrm{m}, \mathrm{n}): \mathrm{f}(\mathrm{m}, \mathrm{n}) \leq \mathrm{T}\}$ (Background pixel) (note, $\mathrm{f}(\mathrm{m}, \mathrm{n})$

3. Nilai rata-rata daritiaphimpunandihitung 
1. $M_{1}=$ nilai rata-rata yaitu $G_{1}$

2. $M_{2}=$ nilai rata-rata yaitu $G_{2}$

4. Sebuahnilai Threshold barudibentuksebagainilai rata-rata dari $M_{1}$ atau $M_{2}$ $\mathrm{T}=\left(M_{1}+M_{2}\right) / 2$

5. Kembali pada langkah 2, sekarang menggunakan nilai Threshold baru yang dikomputasi dalam langkah empat, tetap mengulang hingga sebuah nilai Threshold sama dengan sebelumnya (sampai konvergenter penuhi)

Algoritma iterative ini adalah kasus satu dimensi special dari algoritma clustering k-means, yang telah terbukti untuk mengkonversi nilai minimum lokal yang berarti sebuah nilai threshold inisialisasi yang berbeda dapat memberikan hasil akhir yang berbeda. Dalam pengolahan citra, metode otsu digunakan secara otomatis untuk membentuk thresholding citra berdasarkan bentuk histogram. Dalam metode Otsu kita mencari nilai threshold yang meminimalkan variasi intra-class, didefinisikan sebagai penjumlahan bobot dari variasi dari kedua kelas ;

$$
\begin{array}{ll} 
& \text { Io }(\mathrm{x}, \mathrm{y})=\mathrm{f}(\mathrm{I}(\mathrm{x}, \mathrm{y})) \rightarrow \mathrm{I}(\mathrm{x}, \mathrm{y}) \text { output Io }(\mathrm{x}, \mathrm{y}) \\
\text { 1. } & \mathrm{T}=\mathrm{T}(\mathrm{f}(\mathrm{x}, \mathrm{y})) \\
\text { 2. } & \mathrm{T}=\mathrm{T}[\mathrm{x}, \mathrm{y}, \mathrm{A}(\mathrm{x}, \mathrm{y}), \mathrm{f}(\mathrm{x}, \mathrm{y}) \\
\text { 3. } & \mathrm{T}_{1}<\mathrm{f}(\mathrm{x}, \mathrm{y})<\mathrm{T}_{2} \operatorname{dimana} \mathrm{T}_{1=}\left(\mathrm{V}_{1}+\mathrm{V}_{2}\right) / 2
\end{array}
$$

Tabel1. MSE dan PSNR

\begin{tabular}{|l|l|l|l|}
\hline No & MSE & PSNR & Piksel \\
\hline 1 & 49217,63172 & $-52,6277$ & $\mathrm{r}$ \\
\hline 2 & 48616,63723 & $-52,5046$ & $\mathrm{~g}$ \\
\hline 3 & 49218,69846 & $-52,6274$ & $\mathrm{~b}$ \\
\hline Total & 49017,6558 & $-52,5866$ & rgb \\
\hline
\end{tabular}

1. fungsi mengubah warna ke rgb

void WarnaToRGB(long int warna,int *Red, int

*Green, int *Blue)

\{

$*$ Red = warna \& 0x000000FF;

$*$ Green $=($ warna \& 0x0000FF00 $)>>8$;

$*$ Blue $=($ warna \& 0x00FF0000 $) \gg>16$;

\}

Sebuah gambar akan diambil informasi mengenai 3 warna dasar tiap pixelnya, yaitu merah biru dan hijau, fungsi ini akan memecah gambar menjadi nilainilai warna dasarnya

2. fungsi mengubah rgb ke warna

long int RGBToWarna(int Red, int Green, int Blue)

\{

return $(\operatorname{Red}+($ Green $<<8)+($ Blue $<16))$;

Setiap pixel pada gambar akan diberikan campuran dari 3 warna dasar yang sebelumnya telah dipecah sehingga setiap pixel akan terdiri dari 3 warna dasar tergantung pada intensitasnya

3. merubah gambar ke grayscale

for $(\mathrm{i}=0 ; \mathrm{i}<\mathrm{bm}, \mathrm{bmHeight}, \mathrm{i}++)$

for $(\mathrm{i}=0 ; \mathrm{i}<\mathrm{bm}, \mathrm{bmWidth}, \mathrm{i}++)$

\{

Warna $=$ dcMem 1. GetPixel(j,i);

WarnaToRGB(Warna, \&red, \&green,\&blue);

Gray=int(red+green+blue)/3; 


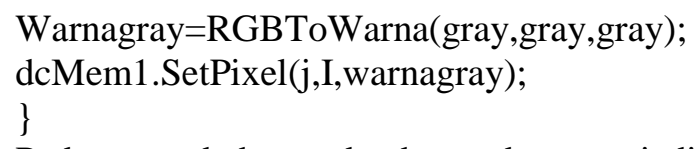

Pada pengubahan sebuah gambar menjadi grayscale dapat dilakukan dengan cara mengambil semua pixel pada gambar kemudian warna tiap pixel akan diambil informasi mengenai 3 warna dasar yaitu merah, biru dan hijau (melalui fungsi warnatoRGB), ketiga warna dasar ini akan dijumlahkan kemudian dibagi tiga sehingga didapat nilai ratarata. Nilai ratarata inilah yang akan dipakai untuk memberikan warna pada pixelgambar sehingga warna menjadi grayscale, tiga warna dasar dari sebuah pixel akan diset menjadi nilai ratarata (melalui fungsi RGBtowarna).

4. Merubah gambar ke biner

for $(\mathrm{i}=0 ; \mathrm{i}<\mathrm{bm}$. bmHeight, $\mathrm{i}++)$

for $(i=0 ; i<b m . b m W i d t h, j++)$

\{

Warna=dcMem1.GetPixel(j,i);

WarnaToRGB(Warna, \&red, \&green,\&blue);

Gray=int(red+green+blue)/3;

If $($ gray $<128)$ gray $=0$;

Else gray $=255$;

Warnagray=RGBToWarna(gray,gray,gray);

\section{APLIKASI DAN PEMBAHASAN}

Sehingga pada penelitian ini digunakan metode otsu thresholding dimana metode thresholding dapat membagi histogram citra gray level ke dalam dua daerah yang berbeda secara otomatis. Penghitungan otsu thresholding terhadap nilai ambang yaitu secara otomatis berdasarkan citra masukan. Analisis diskriminan merupakan pendekatan yang digunakan pada metode otsuthresholding, dengan menentukan suatu variabel yang dapat membedakan antara dua atau lebih kelompok yang muncul secara alami. Untuk memisahkan objek dengan latar belakang analisis diskriminan akan memaksimumkan variabel tersebut. Dengan demikian, Metode otsu thresholding cocok untuk mencari nilai ambang dari sebuah citra serta mendapatkan hasil citra tersegmen yang maksimal.

\subsection{Simple Thresholding}

Dalam simple thresholdingnilaiambangditentukansecara manual antara 0 sampai 1 dalamcontohnilaiambangditentukansebagai

berikutiniadalahcontohdaripenggunaanalgoritma simple thresholding

$$
\text { im1=imread('burung1.png'); }
$$

im2=imread('burung2.png');

bwim $1=$ adaptivethreshold $(\mathrm{im} 1,30,0.01,0)$;

bwim2=adaptivethreshold (im2,30,0.03,0);

Dengan menggunakan thresholding maka derajat keabuan bisa diubah sesuai keinginan, misalkan diinginkan menggunakan derajat keabuan 16, maka tinggal membagi nilai derajat keabuan dengan 16. Proses thresholding ini pada dasarnya adalah proses pengubahan kuantisasi pada citra, sehingga untuk melakukan thresholding dengan derajat keabuan dapat digunakan rumus: 


$$
x=b \cdot \operatorname{int}\left(\frac{w}{b}\right)
$$

dimana:

w adalah nilai derajat keabuan sebelum thresholding $\mathrm{x}$ adalah nilai derajat keabuan setelah thresholding

$$
b=\operatorname{int}\left(\frac{256}{a}\right)
$$

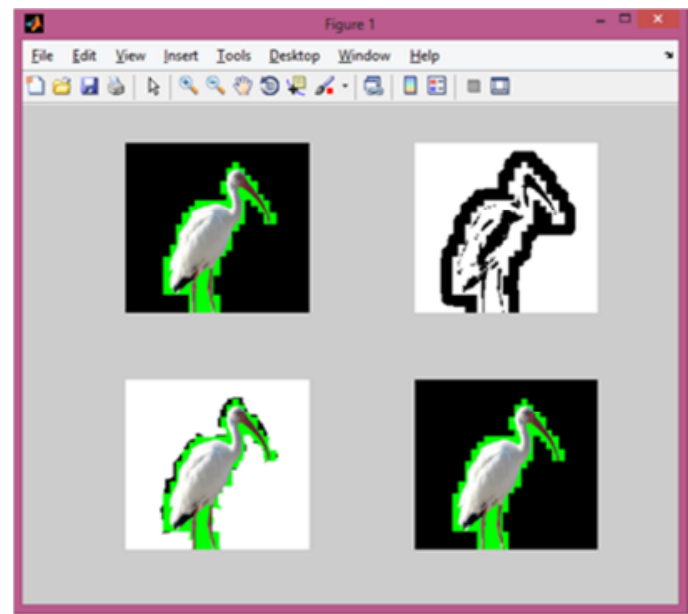

Gambar 1. Orginal Image dan Threshold

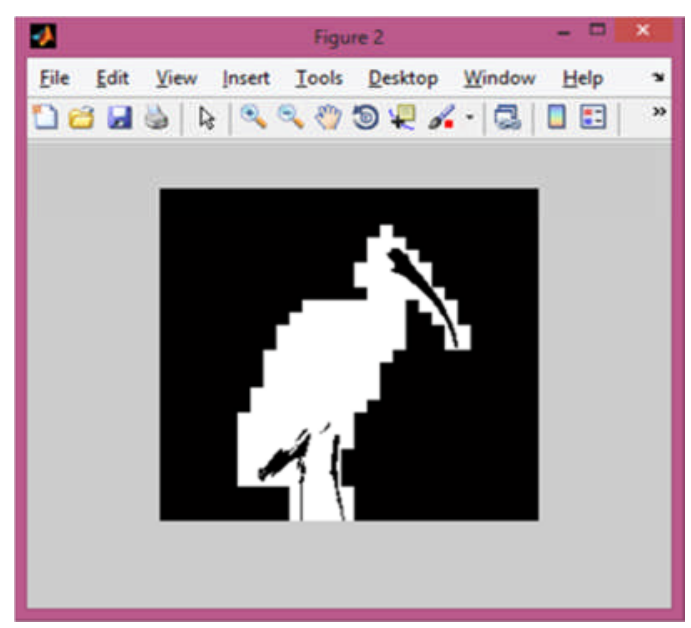

Gambar 2. Graythresh 


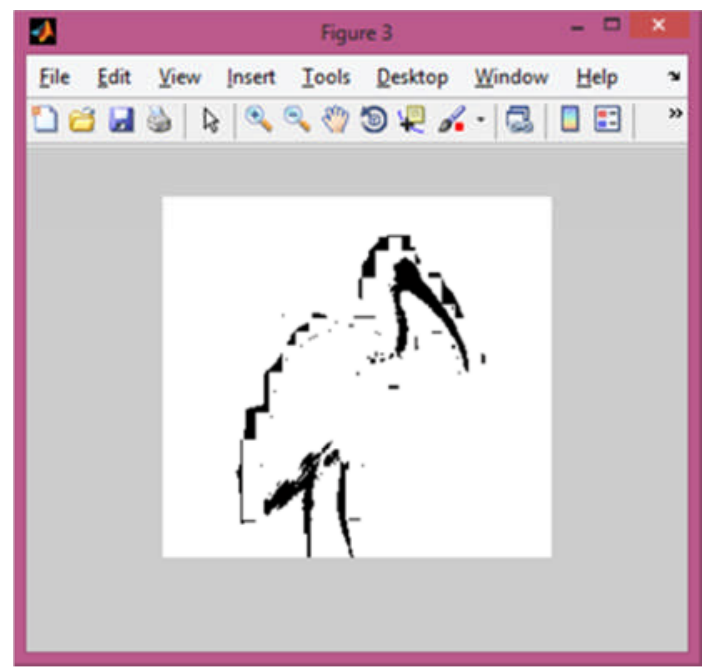

Gambar 3. Graythresh

\subsection{Otsu Thresholding}

Metode otsubertujuan untuk membagi histogram citra keabuan kedalam dua daerah yang berbeda secara otomatis tanpa adanya bantuan dari pengguna untuk memasukkan nilai ambang. Pendekatan yang dilakukan oleh metode otsuyaitu dengan analisis diskriminan yang menentukan suatu variabel sehingga dapat membedakan antara dua atau lebih kelompok yang muncul secara alami. Untuk memisahkan objek dengan latar belakang analisis diskriminan akan memaksimumkan variabel tersebut (Putra, 2004). Untuk mendapatkan nilai threshold ada perhitungan yang harus dilakukan. Langkah awal yang harus dilakukan adalah membuat histogram. Histogram digunakan untuk mengetahui jumlah piksel untuk setiap tingkat keabuan.

Algoritma Otsu thresholdingmenentukansebuahnilaiambang yang ditentukanmelaluisebuahperhitungan.Dalamaplikasimatlabpenentuannilaiambangdidap atsebagaihasildarifungsigraystresh(x)

im1 = imread ('burung1.jpg');

level $=$ graythresh $(\mathrm{im} 1)$

BW = im2bw(im1,level);

Imshow(im1),figure,imshow(BW)

Metode otsu bertujuan untuk membagi histogram citra keabuan kedalam dua daerah yang berbeda secara otomatis tanpa adanya bantuan dari pengguna untuk memasukkan nilai ambang. Pendekatan yang dilakukan oleh metode otsu yaitu dengan analisis diskriminan yang menentukan suatu variabel sehingga dapat membedakan antara dua atau lebih kelompok yang muncul secara alami. Untuk memisahkan objek dengan latar belakang analisis diskriminan akan memaksimumkan variabel tersebut (Putra, 2004). Untuk mendapatkan nilai threshold ada perhitungan yang harus dilakukan. Langkah awal yang harus dilakukan adalah membuat histogram. Histogram digunakan untuk mengetahui jumlah piksel untuk setiap tingkat keabuan.

\subsection{Citra Digital}

Citra digital merupakan bentuk ilustrasi citra yang diambil melalui mesin dengan pendekatan berdasarkan sampling dan kuantisasi. Sampling pada citra menyatakan besar kecilnya ukuran piksel pada citra, dan kuantisasi menyatakan jumlah warna yang ada pada citra 


\subsection{Keabuan (grayscale)}

merubah citra RGB menjadi grayscale merupakan proses awal yang banyak dilakukan dalam pengolahan citra. Citra grayscale adalah pengubahan 3 layer matriks, yaitu R-layer, G-layer dan B-layer menjadi 1 layer matriks grayscale. Dalam citra ini tidak lagi terdapat adanya warna, yang ada adalah derajat keabuan.

\subsection{Kecerahan (brightness)}

Kecerahan merupakan proses perbaikan citra yang dilakukan sebelumproses pengolahan citra agar mendapat hasil yang terbaik. Kecerahan pada citra dapat dilakukan dengan menambah atau mengurangkan sebuah konstanta pada setiap piksel di dalam citra

\subsection{Segmentasi Citra}

Proses segmentasi citra merupakan suatu proses membagi suatu citra menjadi beberapa wilayah yang berbeda. Teknik pada segmentasi citra terbagi menjadi dividing image space dan clustering feature space. Teknik yang pertama yaitu proses segmentasi dengan membagi citra manjadi beberapa bagian untuk mengetahui batasannya, sedangkan teknik yang kedua yaitu dengan memberi index terhadap warna tiap piksel yang menunjukkan bagian dalam suatu segmentasi

\subsection{Morfologi}

Dalam bahasa sehari-hari morfologi berkaitan dengan bentuk dan struktur suatu benda. Di dalam pengolahan citra digital, istilah morfologi digunaka untuk mengolah struktur suatu objek dalam citra demikan rupa sehingga diperoleh struktur objek yang diinginkan. Untuk keperluan pengolahan ini dibutuhkan alat, yaitu matematika morfologi. Matematika morfologi merupakan alat untuk mengekstrak komponenkomponen citra yang berguna dalam representasi dan diskripsi dari suatu bentuk wilayah dalam citra.

Seperti, morfologi juga berguna sebagai langkah awal ataupun akhir dari proses analisis citra (thinning dan filtering). Pendekatan yang digunakan pada morfologi penelitian ini adalah operasi erosi. Erosi merupakan proses yang membandingkan setiap piksel pada citra input dengan nilai structuring elements sehingga pusat structuring elements dapat tepat dengan posisi piksel citra yang diproses

Proses selanjutnya yaitu menampilkan hasil segmentasi dengan metode otsu thresholding dan menampilkan histogram dari hasil segmentasi tersebut dengan menekan tombol "Otsu Thresholding". Serta dengan menampilkan nilai ambang dari proses segmentasi. Selanjutnya proses morfologi dengan pendekatan operasi erosi yaitu menekan tombol "Morfologi (Erosi)" pada tampilan GUI segmentasi untuk menampilkan hasil dari proses morfologi serta menampilkan histogram dari citra morfologi

\section{KESIMPULAN}

Dari penelitian penulis menyarankan dapat menggunakan metode Threshold yang lain sehingga nilai ambang batasnya dapat dibandingkan. Penggunaan matlab dalam pembuatan aplikasi pengolahan citra dalam hal ini untuk proses thresholding dan transformasi citra akan mempersingkat penulisan source code dengan penyediaan fasilitas oleh Matlab. Proses penulisan program yang sekiranya dalam bentuk iterasi digantikan oleh fungsi-fungsi dalam Matlab. Thersholding adalah fungsi matematika yang memotongmotong data menjadi kumpulan-kumpulan frekuensi yang berbeda, sehingga masing-masing komponen tersebut dapat dipelajari dengan menggunakan skala resolusi yang berbeda. Beberapa penerapan transformasi Thresholding pada pengolahan citra digital antara lain preprocessing pengenalan sidik jari, reduksi noise pada citra, steganografi, biometrika dan lain sebagainya.

Penelitian dapat dikembangkan lebih spesifik ke dalam bidang ekstraksi ciri. Pada penelitian selanjutnya dapat dilakukannya eksraksi ciri terhadap daun jambu biji, dimana dengan adanya segmentasi JURNAL SISTEM INFORMASI DAN TEKNOLOGI INFORMASI 
ini akan mengetahui jenis daun jambu biji yang layak maupun tidak layak untuk proses pembuatan obat diare. Parameter yang akan digunakan seperti warna daun, luas daun, tekstur daun, kecacatan daun dll

\section{DAFTAR PUSTAKA}

[1] B. Madduma and S. Ramanna, "Image retrieval based on high level concept detection and semantic labelling," Intell. Decis. Technol., vol. 6, no. 3, pp. 187-196, 2012.

[2] G. Mahalingam and C. Kambhamettu, "Face verification with aging using AdaBoost and local binary patterns," Proc. Seventh Indian Conf. Comput. Vision, Graph. Image Process. - ICVGIP '10, pp. 101-108, 2010.

[3] S. Gao, L. T. Chia, and X. Cheng, "Web image concept annotation with better understanding of tags and visual features," J. Vis. Commun. Image Represent., vol. 21, no. 8, pp. 806-814, 2010.

[4] "BASIC image 2."

[5] C. Procedure, "Image Classification II Supervised Classification," Erdas, pp. 1-11, 2001.

[6] M. K. Sharma and T. J. Siddiqui, "An Ontology Based Framework for Retrieval of Museum Artifacts," Procedia Comput. Sci., vol. 84, pp. 169-176, 2016.

[7] R. Kalam, C. Thomas, and M. Rahiman, "GAUSSIAN KERNEL BASED FUZZY CMeans CLUSTERING ALGORITHM FOR IMAGE SEGMENTATION," Comput. Sci. Inf. Technol., pp. 47-56, 2016.

[8] D. Lu and Q. Weng, "A survey of image classification methods and techniques for improving classification performance," Int. J. Remote Sens., vol. 28, no. 5, pp. 823-870, 2007. 